\title{
Study of Hematological Parameters in End Stage Renal Disease Patients; Those on Regular Hemodialysis as Renal Replacement Therapy
}

\author{
Milind Kesarkhane ${ }^{1}$, Rekha M Haravi ${ }^{2 *}$, Shreekant Kittur ${ }^{3}$, Archana Dambal ${ }^{4}$ \\ ${ }^{1}$ Assistant Professor, Department of IHBT, Government Medical College, Miraj, Pandharpur Rd, Maji Sainik Vasahat, Miraj, Maharashtra 416410, \\ India \\ ${ }^{2}$ Associate Professor, Belgavi Institute of Medical Sciences, Dr B R Ambedkar Rd, Sadashiv Nagar, Belgaum, Karnataka 590019, India \\ ${ }^{3}$ Professor, Department of Pathology, Belgavi Institute of Medical Sciences, Dr B R Ambedkar Rd, Sadashiv Nagar, Belgaum, Karnataka 590019, India \\ ${ }^{4}$ Assistant Professor, Department of General Medicine, Belgavi Institute of Medical Sciences, Dr B R Ambedkar Rd, Sadashiv Nagar, Belgaum,
} Karnataka 590019, India

DOI: $\underline{10.36348 / \text { sjpm.2020.v05i03.003 }}$

| Received: 19.02.2020 | Accepted: 26.02.2020 | Published: 07.03.2020

*Corresponding author: Dr. Rekha M Haravi

\section{Abstract}

In India only few studies are focused on hematological parameters in End Stage Renal Disease (ESRD). This study was undertaken to study haematological parameters in ESRD patients undergoing regular haemodialysis and to compare haematological parameters in these patients before and after haemodialysis. Chronic Kidney Disease is a global public health problem responsible for high morbidity and mortality with greater burden of cost of care especially in developing countries like India. Adult patients with ESRD undergoing regular haemodialysis at Tertiary Care Hospital, Hemodialysis unit were included in the study, irrespective of their etiology. ESRD was diagnosed by nephrologist with creatinine clearance $<15 \mathrm{ml} / \mathrm{min}$ calculated by Cockcroft-Gault equation, biochemical and radiological investigations. With proper aseptic precautions, $5 \mathrm{ml}$ venous blood collected in EDTA vacutainer just before starting haemodialysis and after completion of haemodialysis. Mean age of the patients was $41.03 \pm 12.6$ years with maximum number of male patients with diabetes mellitus with hypertension being most common cause for ESRD. There was statistically significant difference in post haemodialysis value as compared with predialysis value for haemoglobin concentration, hematocrit, RBC count and platelet count. Globally, the dialysis-monitoring strategy is principally based on measurement of biochemical parameters before and after each session of dialysis. This study indicate that most haematological parameters in Hemodialysis patients are significantly altered both pre and post haemodialysis. Thus, monitoring the haematological parameters may help in deciding erythropoietin stimulating agent dose, preventing possible complications and consequently reducing the mortality/morbidity rate in ESRD patients on haemodialysis.

Keywords: Erythropoietin, ESRD, Haemodialysis, Hematological Parameters.

Copyright @ 2020: This is an open-access article distributed under the terms of the Creative Commons Attribution license which permits unrestricted use, distribution, and reproduction in any medium for non-commercial use (NonCommercial, or CC-BY-NC) provided the original author and sources are credited.

\section{INTRODUCTION}

Chronic kidney disease $(\mathrm{CKD})$ is a global public health problem and chronic renal failure (CRF) is a debilitating condition responsible for high morbidity and mortality with greater burden of cost of care especially in developing countries like India. Because of its costs and the complexity of its treatment, proper care is available to very few patients in India. A community-based study has not been done to determine the prevalence of CRF in India [1,2]. CKD adversely affects the haematopoietic system, most common clinical manifestation being anaemia and is often contributing substantially to the morbidity and mortality of the condition [3]. Anaemia is the common sequelae of the chronic kidney disease, associated with significant morbidity. Anaemia of renal failure begins relatively early during the development of kidney disease. As the destruction of the kidney progress, the degree of the anaemia increases. Amongst haematological parameters affected in CKD, haemoglobin concentration and $\mathrm{RBC}$ indices are commonly and severely affected. There is mild to moderate leukocytosis and thrombocytopenia at severe stage of CKD [4].

Haemodialysis (HD) is most common form of renal replacement therapy for CKD stage-V i.e. End Stage Renal Disease (ESRD) worldwide and despite use of recombinant human erythropoietin (rhEPO), anemia $\mathrm{a}$ is frequent finding in HD patients. Anemia may be predictive of an increased risk of mortality in HD patients [5]. Many studies have shown that there is significant change in hematological parameters i.e. 
hemoglobin concentration, RBC count and hematocrit in patient with $\mathrm{CKD}$ after $\mathrm{HD}$ as compared to before HD. Few studies have been done in India comparing haematological parameters before and after $\mathrm{HD}$ in ESRD patients

Altogether changes in the haematological parameters have a major influence in the quality of life of HD patients. So there is need to study change in haematologic parameters in ESRD patients undergoing haemodialysis. The aim was to study haematological parameters in ESRD patients undergoing regular haemodialysis and to compare haematological parameters in these patients pre and post haemodialysis.

\section{MATERIALS AND METHODS \\ Source of Data}

ESRD Patients who are undergoing regular haemodialysis in dialysis unit of tertiary care hospital from south India, from $1^{\text {st }}$ December 2014 to $30^{\text {th }}$ June 2016 irrespective of the cause of CKD. ESRD is diagnosed by clinical features, creatinine clearance $<15$ $\mathrm{ml} / \mathrm{min}$ calculated by Cockcroft-Gault equation ${ }^{6}$, bilateral small kidney visualized on ultrasound or reports of nephrologist when available with the patients.

\section{Method of Collection of Data}

The relevant clinical details were collected from the patients and general physical examination was done. Informed written consent was obtained from the patient for blood investigation and with proper aseptic precautions $5 \mathrm{ml}$ venous blood was collected in EDTA (Ethylene Diamine Tetra-Acetic acid) vacutainer just before starting haemodialysis and after completion of haemodialysis from venous port and arterial port of in vitro circulation of haemodialysis respectively. Blood sample was collected only for one setting of HD for each patient.

The haematological investigations were done at central diagnostic laboratory, Department of Pathology by using automated cell counter (Sysmex KX 21).

Haematological investigations such as $\mathrm{Hb}$ concentration, RBC count, HCT, Red cell indices i.e $\mathrm{MCV}, \mathrm{MCH}, \mathrm{MCHC}$, Reticulocyte count by using new methylene blue, Red cell distribution width (RDW), Total leukocyte count (WBC count), Differential leukocyte count, Platelet count, Peripheral smear- by using Leishman's stain

Sample Size: 39 patients by referring article [7] and by using below formula,

$$
N=\frac{(Z \alpha+Z \beta)^{2} \times s^{2} \times 2}{d^{2}}
$$

Where,

$Z \alpha=Z$ value for alpha level $=1.96$

$\mathrm{Z} \beta=\mathrm{Z}$ value for beta level $=1.28$

$\mathrm{S}=$ common standard deviation between two groups

$\mathrm{d}=$ clinically meaningful difference or mean difference

Study Design: Cross sectional comparative study.

\section{INCLUSION CRITERIA}

- ESRD Patients who are undergoing regular haemodialysis irrespective of etiology of ESRD.

\section{EXCLUSION CRITERIA}

- Patients with haematological malignancy.

- Haemorrhagic episode in past three months.

\section{STATISTICAL ANALYSIS}

Demographic data is represented by tables and charts. The values are expressed in mean \pm Standard deviation (SD). Data is not following normal distribution curve so the median and interquartile range is calculated by using SPSS software and Wilcoxon signed ranks test is applied as test of significance to calculate $\mathrm{p}$ value

\section{RESULTS}

Sixty six adult ESRD patients, 51 males (77.27 $\%)$ and 15 females $(22.73 \%)$ requiring maintenance HD were included in our study. The mean age of male and female patients was $41.03 \pm 12.6$ years and $41.20 \pm 10.31$ years respectively. Overall mean age was $41.03 \pm 12.6$ years.

The causes for ESRD are varied. Most common cause for ESRD was diabetes along with hypertension $(46.96 \%)$ followed by diabetes alone $(22.7 \%)$ and hypertension alone $(22.7 \%)$. Other causes were polycystic kidney disease (PCKD) (4.5\%), systemic lupus erythematosis (SLE) involving kidney $(3 \%)$, obstructive uropathy $(3 \%)$ and interstitial nephritis (1.5\%) were other causes for the ESRD.

Time period of these patients on haemodialysis varied from 2 years to 11 years. Maximum number of patients $(77.27 \%)$ were on HD for period of less than 5 years.

Following table shows pre haemodialysis and post haemodialysis values for various haematological parameters in patients with CKD stage $\mathrm{V}$. These values are expressed in mean $\pm \mathrm{SD}$.

Mean \pm SD of pre HD and post HD for haemoglobin concentration, RBC count, Hematocrit and platelet count was statistically significant. ( $\mathrm{p}$ value $<0.05)$ 
Mean \pm SD of pre $\mathrm{HD}$ and post $\mathrm{HD}$ of MCV.MCH, MCHC, total leukocyte count, differential leukocyte count, RDW and reticulocyte count were shown in table 7 with $\mathrm{p}$ value $>0.05$ which was statistically insignificant.

There was significant change of increase in haemoglobin concentration, RBC count, HCT and decrease in platelet count in post HD values as compared to pre HD values. There was no significant change in total leukocyte count, differential leukocyte count and RBC indices.

Most common peripheral blood smear finding was normocytic normochromic anaemia (84.84\%) followed by microcytic hypochromic anaemia $(9.09 \%)$ and macrocytic anaemia $(6.06 \%)$. There were no changes in peripheral blood smear finding post HD as compared to pre HD

Table-1: Pre HD and Post HD haematological parameters in CKD stage V patients (expressed in mean \pm SD) and p value

\begin{tabular}{|l|l|l|l|}
\hline Variables & Pre HD & Post HD & p value \\
\hline $\mathrm{Hb}(\mathrm{g} / \mathrm{dl})$ & $8.60 \pm 2.02$ & $9.93 \pm 2.45$ & $\mathbf{0 . 0 0 1}$ \\
\hline $\mathrm{RBC}$ count $\left(\mathrm{x} 10^{6} / \mu \mathrm{l}\right)$ & $3.11 \pm 0.65$ & $3.51 \pm 0.82$ & $\mathbf{0 . 0 0 1}$ \\
\hline $\mathrm{HCT}(\%)$ & $26.89 \pm 6.13$ & $30.83 \pm 7.45$ & $\mathbf{0 . 0 0 1}$ \\
\hline $\mathrm{MCV}(\mathrm{fL})$ & $86.05 \pm 8.52$ & $86.89 \pm 8.36$ & 0.006 \\
\hline $\mathrm{MCH}(\mathrm{pg})$ & $27.66 \pm 3.22$ & $27.51 \pm 3.17$ & 0.023 \\
\hline $\mathrm{MCHC}(\mathrm{g} / \mathrm{dl})$ & $31.94 \pm 1.30$ & $31.88 \pm 1.21$ & 0.557 \\
\hline RDW $(\mathrm{SD} \mathrm{fl})$ & $46.82 \pm 4.62$ & $46.75 \pm 4.61$ & 0.886 \\
\hline WBC count $\left(\mathrm{x} 10^{3} / \mu \mathrm{l}\right)$ & $5.60 \pm 2.03$ & $5.52 \pm 1.71$ & 0.622 \\
\hline DLC- Neutrophils $(\%)$ & $64.93 \pm 6.23$ & $64.60 \pm 6.20$ & 0.806 \\
\hline DLC- Lymphocytes $(\%)$ & $56.98 \pm 10.62$ & $57.50 \pm 9.97$ & 0.920 \\
\hline DLC- Eosinophils $(\%)$ & $4.84 \pm 2.74$ & $4.62 \pm 2.67$ & 0.594 \\
\hline DLC- Monocytes $(\%)$ & $0.93 \pm 0.89$ & $0.86 \pm 0.85$ & 0.437 \\
\hline Platelet counts $\left(\mathrm{x} 10^{3} / \mu \mathrm{l}\right)$ & $1.94 \pm 0.75$ & $1.55 \pm 0.60$ & $\mathbf{0 . 0 0 1}$ \\
\hline
\end{tabular}

Table-2: Comparison of various studies of haemoglobin concentration pre HD and post HD

\begin{tabular}{|l|l|l|l|}
\hline \multirow{2}{*}{ Studies } & Haemoglobin concentration $(\mathbf{g} / \mathbf{d l})($ expressed in mean \pm SD $)$ & p value \\
\cline { 2 - 3 } & Pre HD & Post HD & \\
\hline Present study & $\mathbf{8 . 6 0} \pm \mathbf{2 . 0 2}$ & $\mathbf{9 . 9 3} \pm \mathbf{2 . 4 5}$ & $\mathbf{0 . 0 0 1}$ \\
\hline Costa et al.,[15] & $12.10 \pm 1.85$ & $13.20 \pm 3.45$ & 0.001 \\
\hline Pereira et al., [16] & $11.77 \pm 1.29$ & $13.11 \pm 1.68$ & 0.001 \\
\hline Jaroszynski et al., [17] & $10.91 \pm 1.43$ & $12.36 \pm 1.58$ & 0.002 \\
\hline Rangel et al., [18] & $9.60 \pm 2.02$ & $11.45 \pm 2.45$ & 0.001 \\
\hline Geller et al., [19] & $10.2 \pm 2.12$ & $12.03 \pm 2.05$ & 0.001 \\
\hline Mohamed et al., [20] & $10.43 \pm 1.44$ & $10.65 \pm 1.58$ & 0.002 \\
\hline Małyszko et al., [21] & $11.77 \pm 1.20$ & $11.94 \pm 1.48$ & 0.124 \\
\hline Vickers et al., [22] & $10.60 \pm 1.48$ & $11.01 \pm 2.33$ & 0.557 \\
\hline Inagaki et al., [23] & $10.91 \pm 2.44$ & $11.03 \pm 2.54$ & 0.068 \\
\hline
\end{tabular}

Table-3: Comparison of various studies of RBC count pre HD and post HD

\begin{tabular}{|l|l|l|l|}
\hline \multirow{2}{*}{ Studies } & RBC count $(\mathbf{x ~ 1 0} / \boldsymbol{\mu l})($ expressed in mean \pm SD $)$ & \multirow{2}{*}{ p value } \\
\cline { 2 - 3 } & Pre HD & Post HD & \\
\hline Present study & $\mathbf{3 . 1 1} \pm \mathbf{0 . 6 5}$ & $\mathbf{3 . 5 1} \pm \mathbf{0 . 8 2}$ & $\mathbf{0 . 0 0 1}$ \\
\hline Costa et al., $[15]$ & $3.96 \pm 0.44$ & $4.20 \pm 1.44$ & 0.010 \\
\hline Pereira et al., [16] & $4.07 \pm 0.29$ & $4.61 \pm 0.68$ & 0.001 \\
\hline Jaroszynski et al., [17] & $3.56 \pm 0.53$ & $4.01 \pm 0.68$ & 0.005 \\
\hline Rangel et al., [18] & $4.01 \pm 0.02$ & $4.98 \pm 0.45$ & 0.001 \\
\hline Geller et al., [19] & $4.02 \pm 0.01$ & $4.78 \pm 0.15$ & 0.001 \\
\hline Mohamed et al., [20] & $4.01 \pm 0.45$ & $4.98 \pm 0.45$ & 0.001 \\
\hline Małyszko et al., [21] & 3.68 & 3.70 & 0.457 \\
\hline Vickers et al., [22] & $3.46 \pm 1.53$ & $4.01 \pm 1.64$ & 0.248 \\
\hline
\end{tabular}


Table-4: Comparison of various studies of haematocrit pre HD and post HD

\begin{tabular}{|l|l|l|l|}
\hline \multirow{2}{*}{ Studies } & \multicolumn{2}{l|}{ HCT $(\%)($ expressed in mean \pm SD $)$} & p value \\
\cline { 2 - 4 } & Pre HD & Post HD & \\
\hline Present study & $\mathbf{2 6 . 8 9} \pm \mathbf{6 . 1 3}$ & $\mathbf{3 0 . 8 3} \pm \mathbf{7 . 4 5}$ & $\mathbf{0 . 0 0 1}$ \\
\hline Costa et al., $[15]$ & $32.10 \pm 4.85$ & $34.20 \pm 3.99$ & 0.001 \\
\hline Pereira et al., $[16]$ & $30.4 \pm 6.8$ & $32.12 \pm 8.3$ & 0.001 \\
\hline Jaroszynski et al., $[17]$ & $28.91 \pm 5.43$ & $30.36 \pm 6.18$ & 0.002 \\
\hline Rangel et al., $[18]$ & $27.88 \pm 6.13$ & $29.63 \pm 6.47$ & 0.001 \\
\hline Geller et al.. $[19]$ & $31.4 \pm 4.8$ & $33.12 \pm 4.91$ & 0.001 \\
\hline Mohamed et al., $[20]$ & $28.23 \pm 5.63$ & $30.16 \pm 6.01$ & 0.002 \\
\hline Vickers et al.. $[22]$ & $30.4 \pm 6.8$ & $30.22 \pm 6.3$ & 0.058 \\
\hline Inagaki et al., $[23]$ & $28.41 \pm 4.46$ & $26.17 \pm 5.15$ & 0.658 \\
\hline Małyszko et al., $[21]$ & $31.4 \pm 4.7$ & $32.02 \pm 4.90$ & 0.265 \\
\hline
\end{tabular}

Table-5: Comparison of various studies of platelet count pre HD and post HD

\begin{tabular}{|c|c|c|c|}
\hline \multirow[t]{2}{*}{ Studies } & \multicolumn{2}{|c|}{$\begin{array}{l}\text { Platelet count }\left(\times 10^{6} / \mu \mathrm{l}\right) \\
(\text { expressed in mean } \pm \mathrm{SD})\end{array}$} & \multirow[t]{2}{*}{ p value } \\
\hline & Pre HD & \begin{tabular}{|l|} 
Post HD \\
\end{tabular} & \\
\hline Present study & $1.94 \pm 0.75$ & $1.55 \pm 0.60$ & $<0.001$ \\
\hline Yeniçerioglu et al., [24] & $2.44 \pm 1.70$ & $2.05 \pm 1.53$ & 0.001 \\
\hline Pereira et al., [16] & $1.92 \pm 0.98$ & $1.63 \pm 0.75$ & 0.001 \\
\hline Jaroszynski et al., [17] & $2.24 \pm 1.67$ & $1.95 \pm 1.55$ & 0.001 \\
\hline Rangel et al., [18] & $1.84 \pm 0.80$ & $1.33 \pm 0.63$ & 0.0001 \\
\hline Geller et al., [19] & $1.72 \pm 0.56$ & $1.63 \pm 0.63$ & 0.002 \\
\hline Mohamed et al., [20] & $2.24 \pm 0.67$ & $2.35 \pm 0.45$ & 0.568 \\
\hline Sloand and Sloand [25] & $1.84 \pm 0.49$ & $1.93 \pm 0.76$ & 0.068 \\
\hline Romao et al., [26] & $1.99 \pm 0.46$ & $2.13 \pm 0.68$ & 0.094 \\
\hline Ulusoy et al., [27] & $2.30 \pm 1.74$ & $2.05 \pm 1.40$ & 0.475 \\
\hline
\end{tabular}

\section{DISCUSSION}

Chronic renal failure is a major health problem and it greatly affects the economic and social status of affected patients. In India Hemodialysis (HD) treatment remains the principal method of treatment for correcting the renal dysfunction $[8,30]$. HD increases longevity of ESRD patients by removing the metabolic end products and excess of water [9, 31, 32]. The results of this present study show that the ESRD patients on regular $H D$ display degrees of changes of various haematological parameters which are different from hematological changes in CKD patients in general.

Monitoring haemoglobin concentration response over time is a critical step in anaemia management of ESRD patients. An estimation of true haemoglobin concentration from insufficient data without accounting for short-term variability may lead to inappropriate or unnecessary dose adjustments, leading to haemoglobin concentration cycling and exposing patients to harmful side effects of ESA and blood transfusion [10-12, 29]. At this time, no clinically accepted standard exists for the frequency of haemoglobin concentration monitoring, and dialysis facilities use a variety of schedules, ranging from weekly to once every 5 weeks (monthly).

The NKF KDOQITM guidelines published in 2006 [13] recommended weekly haemoglobin concentration monitoring after ESA initiation or dose adjustment, but recognized that "... there are no reported studies that have systematically compared different protocols (i.e., different frequencies of haemoglobin concentration /Hct measurements) for monitoring the haemoglobin concentration /Hct response to Epoetin therapy ..." Several researchers have attempted to systematically study haemoglobin concentration observation frequency. Khan and Krishnan [14] retrospectively analyzed the relationship between haemoglobin concentration monitoring frequency and haemoglobin concentration variability from 3212 U.S. dialysis facilities. They reported that more frequent haemoglobin concentration monitoring was associated with less haemoglobin concentration variability and hence clinical impact.

The mean platelet count in the present study showed a significance decrease in patients post-HD when compared to pre-HD counts. This finding is in agreement with findings of study done by Yeniçerioglu et al., Pereira et al., Jaroszynski et al., Rangel et al., and Geller et al., who reported a significant decrease in circulating platelets post-HD when compared to the preHD counts [16-19, 24.

Present study results are not in accordance with study done by Mohamed et al. found that there were no statistically significant differences between the mean platelets count post-HD when compared to preHD counts [20]. Likewise, other studies by Sloand and 
Sloand, Romao et al., Ulusoy et al., reported that there were no significant differences in platelets counts between the pre- and post-HD counts [25-27].

The decrease in platelet count post-HD may be due to either the HD procedure itself, through the interaction of blood with membranes that may activate complement or to the heparin used during dialysis was one of the factors accounting for the increased platelet aggregation after dialysis.

In a study done by Docci et al., stated that the dialysis membrane composition is a major factor influencing hemodialysis-associated platelet loss [28].

\section{Peripheral Blood Smear}

Present study showed most common peripheral blood smear finding is normocytic normochromic anemia $(81.81 \%)$ followed by microcytic hypochromic anemia $(9.09 \%)$, macrocytic anemia $(6.06 \%)$ and normocytic normochromic anaemia with thrombocytopenia. Study done by Pereira et al., Costa et al., Rangel et al., and Geller et al., also showed that most common peripheral blood smear finding were normocytic normochromic anaemia [15-19].

There were no changes in peripheral blood smear finding post HD as compared to pre HD

\section{CONCLUSION}

The results of present study showed changes in the haematological parameters post HD as compared to pre HD in ESRD patients on HD. There was statistically significant increase in haemoglobin concentration, haematocrit, $\mathrm{RBC}$ count and decrease in platelet count post-HD as compared to pre HD values. Altered platelets count is usually suggestive of bleeding and thrombosis tendency.

Globally, the dialysis-monitoring strategy is principally based on measurement of biochemical parameters before and after each session of dialysis. Statistically significant change in most haematological parameters post HD as compared to pre HD could be due to haemodilution, HD procedure itselt or heparin used during HD. There is a probability that these changes could have clinical implications. Thus, monitoring the hematological parameters may help in preventing possible complications, and consequently reducing the mortality/morbidity rate.

However, further randomized and controlled studies are necessary to support this hypothesis. Further research studies are necessary to follow up patients through at least three HD sessions while continuously measuring their haematological and haemostatic parameters. Data from such studies corroborated with clinical data, will be more representative of the effect of HD on haematological parameters.

\section{REERENCES}

1. Varma, P. P. (2015). Prevalence of chronic kidney disease in India-Where are we heading?. Indian journal of nephrology, 25(3), 133-135.

2. Afshar, R., Sanavi, S., Salimi, J., \& Ahmadzadeh, M. (2010). Hematological profile of chronic kidney disease (CKD) patients in Iran, in predialysis stages and after initiation of hemodialysis. Saudi Journal of Kidney Diseases and Transplantation, 21(2), 368-371.

3. Means, R. T., Greer, J., Foerster, J., \& Rodgers, M. G. (2009). Anemia of chronic renal insufficiency. In, Wintrobe's clinical hematology. $12^{\text {th }}$ ed. Philadelphia, Lippincott-Williams \& Wilkins; 1225-1229.

4. Mishra, R., Singh, R. G., Mishra, C. P., Singh, S., \& Tiwari, P. N. (2014). Anaemia in chronic kidney disease patients and its relation to GFR and socio-demographic profile. Indian Journal of Preventive \& Social Medicine, 45(1-2), 53-57.

5. Olasunkanmi, S., Adindu, C., Sikiru, B., \& Mohammed, M. (2013). Hematological profile of patients with chronic kidney disease in Nigeia. JNRT, 5(1):02-10.

6. Ganong, W. F. (2007). Formation and excretion of urine. In, Review of medical physiology, $22^{\text {nd }}$ edition. Mc Graw Hill; 699-24.

7. Bhatta, S., Aryal, G., \& Kafle, R. K. (2011). Anemia in chronic kidney disease patients in predialysis and postdialysis stages. Journal of Pathology of Nepal, 1(1), 26-29.

8. Madore, F., Lowrie, E. G., Brugnara, C., Lew, N. L., Lazarus, J. M., Bridges, K., \& Owen, W. F. (1997). Anemia in hemodialysis patients: variables affecting this outcome predictor. Journal of the American Society of Nephrology,8(12), 19211929.

9. Lechner, M. S., \& Dressler, G. R. (1997). The molecular basis of embryonic kidney development. Mechanisms of development, 62(2), 105-120.

10. Goddard, J., Turner, A. N., \& Stewart, L. H. (2010). Kidney and urinary tract disease. In, Nicki, R. C. (Ed). Davidson's Principles and Practice of Medicine, $21^{\text {st }}$ edition. Edinburg Elsevier, 490491.

11. National Kidney Foundation. (2001). K/DOQI clinical Practice Guidelines 2000 update. Am Journal Kidney Dis; 37 (suppl 1):207.

12. Charles, E. A., \& Anthony, C. (2014). The kidney. In, Vinay, K. A., Abul, K. A. (Ed). Robbins and cotran Pathologic basis of disease, $9^{\text {th }}$ edition. Edinburg Elsevier; 898-899.

13. National Kidney Foundation. (2006). KDOQI clinical practice guidelines and clinical practice recommendations for anemia in chronic kidney disease. Am J Kidney Dis, 47(3), S1-S146.

14. Khan, I., \& Krishnan, M. (2007, April). Frequency of $\mathrm{Hb}$ monitoring in dialysis units is associated with facility-level $\mathrm{Hb}$ variability. In 2007 Spring 
Clinical Meeting of the National Kidney Foundation. Orlando, FL.

15. Costa, E., Rocha, S., Rocha-Pereira, P., Castro, E., Miranda, V., Faria, M. D. S., ... \& Santos-Silva, A. (2008). Changes in red blood cells membrane protein composition during hemodialysis procedure. Renal failure, 30(10), 971-975.

16. Pereira, R., Costa, E., Gonçalves, M., Miranda, V., Sameiro Faria, M. D., Quintanilha, A., ... \& SANTOS- SILVA, A. (2010). Neutrophil and monocyte activation in chronic kidney disease patients under hemodialysis and its relationship with resistance to recombinant human erythropoietin and to the hemodialysis procedure. Hemodialysis International, 14(3), 295-301.

17. Jaroszyński, A. J., Głowniak, A., Sodolski, T., Załuska, W., Widomska-Czekajska, T., \& Książek, A. (2006). Effect of haemodialysis on signal-averaged electrocardiogram P-wave parameters. Nephrology Dialysis Transplantation, 21(2), 425-430.

18. Rangel, É. B., Andreoli, M. C., Matos, A. C. C., Guimaraes-Souza, N. K., Mallet, A. C., Carneiro, F. D., \& Santos, B. C. (2010). Hemoglobin and hematocrit at the end of hemodialysis: a better way to adjust erythropoietin dose?. Journal of Artificial Organs, 13(1), 63-66.

19. Geller, A. B., DeVita, M. V., Marku- Podvorica, J., Rosenstock, J. L., Panagopoulos, G., \& Michelis, M. F. (2010). Increase in post- dialysis hemoglobin can be out of proportion and unrelated to ultrafiltration. Dialysis \& Transplantation, 39(2), 57-62.

20. Ali, M. S. M., Babiker, M. A., Merghani, L. B., Ali, F. A. A. T., \& Abdulmajeed, M. H. (2008). Hematological changes post-hemo and peritoneal dialysis among renal failure patients in Sudan. Saudi Journal of Kidney Diseases and Transplantation, 19(2), 274-279.

21. Malyszko, J., Zbroch, E., Wolczyński, S., Malyszko, J. S., \& Myśliwiec, M. (1999). Leptinaemia in patients dialysed with different buffers and dialysis membranes. Nephrology Dialysis Transplantation, 14(10), 2527-2529.

22. Vickers, J., Losche, W., Dopel, E., Heptinstall, S., Stein, G., \& Spangenberg, P. (1998). Measurement of platelet activation and adhesion to leukocytes during haemodialysis. Platelets, 9(34), 261-264.

23. Inagaki, H., Kuroda, M., Watanabe, S., \& Hamazaki, T. (2001). Changes in major blood components after adopting the supine position during haemodialysis. Nephrology Dialysis Transplantation, 16(4), 798-802.

24. Yenicerioglu, Y., Sahin, S. S., Capa, G., Abadoglu, O., Camsar, T., Altan, R., ... \& Uçan, E. S. (2000). Effects of haemodialysis on pulmonary clearance of Tc-99m diethylene triamine pentaacetate (DTPA). Scandinavian journal of urology and nephrology, 34(2), 126130.

25. Sloand, J. A., \& Sloand, E. M. (1997). Studies on platelet membrane glycoproteins and platelet function during hemodialysis. Journal of the American Society of Nephrology, 8(5), 799-803.

26. Romao Jr, J. E., Fadil, M. A., Sabbaga, E., \& Marcondes, M. (1997). Haemodialysis without anticoagulant: haemostasis parameters, fibrinogen kinetic, and dialysis efficiency. Nephrology, dialysis, transplantation: official publication of the European Dialysis and Transplant Association-European Renal Association, 12(1), 106-110.

27. Ulusoy, S., Ovali, E., Aydin, F., Erem, C., Ozdemir, F., \& Kaynar, K. (2004). Hemostatic and fibrinolytic response to nasal desmopressin in hemodialysis patients. Medical Principles and Practice, 13(6), 340-345.

28. Docci, D., Turci, F., Del Vecchio, C., Bilancioni, R., Cenciotti, L., \& Pretolani, E. (1984). Hemodialysis-associated platelet loss: study of the relative contribution of dialyzer membrane composition and geometry. The International journal of artificial organs, 7(6), 337-340.

29. Snyder, S., \& Pendergraph, B. E. R. N. A. D. E. T. T. E. (2005). Detection and evaluation of chronic kidney disease. American family physician, 72(9), 1723-1732.

30. Rajapurkar, M. M., John, G. T., Kirpalani, A. L., Abraham, G., Agarwal, S. K., Almeida, A. F., ... \& Pisharody, R. (2012). What do we know about chronic kidney disease in India: first report of the Indian CKD registry. BMC nephrology, 13(1), 10.

31. Centers for Disease Control and Prevention (CDC. (2007). Prevalence of chronic kidney disease and associated risk factors--United States, 19992004. MMWR. Morbidity and mortality weekly report, 56(8), 161-165.

32. National Kidney Disease Education Program. (2004). African Americans \& kidney disease fact sheet. Bethesda, Md: National Institute of Diabetes and Digestive and Kidney Diseases, National Institutes of Health (NIH), U.S. Department of Health \& Human Services. NIH publication no. 04-5577. (Rev April 2006). Available at http://nkdep.nih.gov/news/campaign/african_amer icans_508.pdf.

33. Singh, N. P., Ingle, G. K., Saini, V. K., Jami, A., Beniwal, P., Lal, M., \& Meena, G. S. (2009). Prevalence of low glomerular filtration rate, proteinuria and associated risk factors in North India using Cockcroft-Gault and Modification of Diet in Renal Disease equation: an observational, cross-sectional study. BMC nephrology, 10(1), 4. 